\title{
Early Revascularization in Acute Myocardial Infarction Complicated by Cardiogenic Shock
}

\section{Citation}

Hochman, Judith S., Lynn A. Sleeper, John G. Webb, Timothy A. Sanborn, Harvey D. White, J. David Talley, Christopher E. Buller, et al. 1999. "Early Revascularization in Acute Myocardial Infarction Complicated by Cardiogenic Shock." New England Journal of Medicine 341 (9) (August 26): 625-634. doi:10.1056/nejm199908263410901.

\section{Published Version}

doi:10.1056/NEJM199908263410901

\section{Permanent link}

http://nrs.harvard.edu/urn-3:HUL.InstRepos:29666958

\section{Terms of Use}

This article was downloaded from Harvard University's DASH repository, and is made available under the terms and conditions applicable to Other Posted Material, as set forth at http:// nrs.harvard.edu/urn-3:HUL.InstRepos:dash.current.terms-of-use\#LAA

\section{Share Your Story}

The Harvard community has made this article openly available.

Please share how this access benefits you. Submit a story.

\section{Accessibility}




\title{
The New England Journal of Medicine
}

(C) Copyright, 1999, by the Massachusetts Medical Society

\section{EARLY REVASCULARIZATION IN ACUTE MYOCARDIAL INFARCTION COMPLICATED BY CARDIOGENIC SHOCK}

\author{
Judith S. Hochman, M.D., Lynn A. Sleeper, Sc.D., John G. Webb, M.D., Timothy A. Sanborn, M.D., \\ Harvey D. White, D.Sc., J. David Talley, M.D., Christopher E. Buller, M.D., Alice K. Jacobs, M.D., \\ James N. Slater, M.D., Jacoues Col, M.D., Sonja M. McKinlay, Ph.D., and Thierry H. LeJemtel, M.D., \\ FOR THE SHOCK INVESTIGATORS*
}

\section{AbStRACT}

Background The leading cause of death in patients hospitalized for acute myocardial infarction is cardiogenic shock. We conducted a randomized trial to evaluate early revascularization in patients with cardiogenic shock.

Methods Patients with shock due to left ventricular failure complicating myocardial infarction were randomly assigned to emergency revascularization (152 patients) or initial medical stabilization (150 patients). Revascularization was accomplished by either coronary-artery bypass grafting or angioplasty. Intraaortic balloon counterpulsation was performed in 86 percent of the patients in both groups. The primary end point was mortality from all causes at 30 days. Six-month survival was a secondary end point.

Results The mean ( $\pm \mathrm{SD}$ ) age of the patients was $66 \pm 10$ years, 32 percent were women, and 55 percent had been transferred from other hospitals. The median time to the onset of shock was 5.6 hours after infarction, and most infarcts were anterior in location. Ninety-seven percent of the patients assigned to revascularization underwent early coronary angiography, and 87 percent underwent revascularization; only 2.7 percent of the patients assigned to medical therapy crossed over to early revascularization without clinical indication. Overall mortality at 30 days did not differ significantly between the revascularization and medical-therapy groups (46.7 percent and 56.0 percent, respectively; difference, -9.3 percent; 95 percent confidence interval for the difference, -20.5 to 1.9 percent; $\mathrm{P}=0.11$ ). Six-month mortality was lower in the revascularization group than in the medical-therapy group (50.3 percent vs. 63.1 percent, $\mathrm{P}=0.027$ ).

Conclusions In patients with cardiogenic shock, emergency revascularization did not significantly reduce overall mortality at 30 days. However, after six months there was a significant survival benefit. Early revascularization should be strongly considered for patients with acute myocardial infarction complicated by cardiogenic shock. (N Engl J Med 1999;341:625-34.) (C)1999, Massachusetts Medical Society.

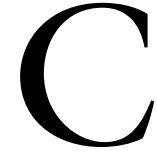

ARDIOGENIC shock complicates 7 to 10 percent of cases of acute myocardial infarction and is associated with a 70 to 80 percent mortality rate. ${ }^{1,2}$ Cardiogenic shock remains the leading cause of death in patients hospitalized with myocardial infarction in the reperfusion era. ${ }^{3,4}$ Nonrandomized studies report markedly lower mortality rates among patients who have undergone revascularization for shock. ${ }^{5-16}$ However, selection bias is evident. ${ }^{17,18}$ In small series of patients undergoing early primary angioplasty for cardiogenic shock, in-hospital mortality rates ranged from 26 percent to 72 percent. ${ }^{16,17} \mathrm{~A}$ prematurely terminated randomized trial comparing angioplasty with conventional therapy for shock in $\mathbf{5 5}$ patients reported no difference in mortality. ${ }^{19}$

From St. Luke's-Roosevelt Hospital Center and Columbia University, New York (J.S.H., J.N.S.); New England Research Institutes, Watertown, Mass. (L.A.S., S.M.M.); St. Paul's Hospital, Vancouver, B.C., Canada (J.G.W.); New York Hospital-Cornell Medical Center, New York (T.A.S.); Green Lane Hospital, Auckland, New Zealand (H.D.W.); the University of Arkansas, Little Rock (J.D.T); Vancouver General Hospital, Vancouver, B.C., Canada (C.E.B.); Boston Medical Center, Boston (A.K.J.); Cliniques Universitaires St. Luc, Brussels, Belgium (J.C.); and Albert Einstein College of Medicine, Bronx, N.Y. (T.H.L.). Address reprint requests to Dr. Hochman at St. Luke's-Roosevelt Hospital Center, 1111 Amsterdam Ave., New York, NY 10025.

Other authors were Michael H. Picard, M.D., Massachusetts General Hospital, Boston; Mark A. Menegus, M.D., Montefiore Medical CenterAlbert Einstein College of Medicine, Bronx, N.Y.; Jean Boland, M.D., Centre Hospitalier Régional Citadelle, Liege, Belgium; Vladimir Dzavik, M.D., University of Alberta Hospital, Edmonton, Alta., Canada; Christopher R. Thompson, M.D., C.M., St. Paul's Hospital, Vancouver, B.C., Canada; S. Chiu Wong, M.D., New York Hospital Medical Center of Queens, Flushing, N.Y.; Richard Steingart, M.D., Winthrop University Hospital, Mineola, N.Y.; Robert Forman, M.D., Albert Einstein College of Medicine, Bronx, N.Y.; Philip E. Aylward, B.M., B.Ch., Ph.D., Flinders Medical Centre, Adelaide, S.A., Australia; Emilie Godfrey, M.S., R.D., St. Luke's-Roosevelt Hospital Center, New York; and Patrice Desvigne-Nickens, M.D., National Heart, Lung, and Blood Institute, Bethesda, Md.

*The participants in the SHOCK (Should We Emergently Revascularize Occluded Coronaries for Cardiogenic Shock) trial are listed in the Appendix. 
Most patients with cardiogenic shock do not undergo emergency revascularization, either because of the lack of facilities at the hospitals where they present or because of doubt as to its efficacy. ${ }^{18,20-22}$ If early revascularization reduces mortality, angioplasty or coronary-artery bypass graft surgery should be performed on an urgent basis, even if this requires transfer to a hospital with the necessary facilities and expertise.

We report the primary results of a randomized trial evaluating emergency revascularization therapy for myocardial infarction complicated by cardiogenic shock.

\section{METHODS}

\section{Study Design}

The study was a randomized trial comparing two treatment strategies: emergency revascularization (referred to as revascularization) and initial medical stabilization (referred to as medical therapy). From April 1993 to November 1998, patients from 30 sites were enrolled by means of computerized telephone randomization, with randomization at each site performed according to a permuted-block design. A registry of patients with suspected cardiogenic shock as a complication of myocardial infarction was compiled concurrently through August 1997.23 For patients assigned to revascularization, angioplasty or bypass surgery had to be performed as soon as possible and within six hours of randomization; intraaortic balloon counterpulsation was recommended. For patients assigned to medical stabilization, intensive medical therapy was required. Intraaortic balloon counterpulsation and thrombolytic therapy were recommended. Delayed revascularization at a minimum of $\mathbf{5 4}$ hours after randomization was recommended if clinically appropriate. Coronary angiograms were reviewed at the core laboratory by two independent readers, with discrepancies resolved by a third reader. All readers were blinded to enrolling site and treatment group.

The primary end point of the study was overall mortality 30 days after randomization. Secondary end points consisted of overall mortality 6 and 12 months after infarction. Details of the trial design have been previously published. ${ }^{24}$ The protocol was reviewed and approved by the institutional review board or ethics committee at each site. Written informed consent was obtained from either the patient or a surrogate. Two of the study centers received approval to follow the procedure specified by the $\mathrm{Na}-$ tional Institutes of Health and the Food and Drug Administration for exemption from informed consent. ${ }^{24}$

\section{Eligibility Criteria}

Eligible patients had ST-segment elevation, a Q-wave infarction, a new left bundle-branch block, or a posterior infarction with anterior ST-segment depression, complicated by shock due predominantly to left ventricular dysfunction. Cardiogenic shock was confirmed by both clinical and hemodynamic criteria. The clinical criteria were hypotension (a systolic blood pressure of $<90 \mathrm{~mm} \mathrm{Hg}$ for at least 30 minutes or the need for supportive measures to maintain a systolic blood pressure of $\geqslant 90 \mathrm{~mm} \mathrm{Hg}$ ) and end-organ hypoperfusion (cool extremities or a urine output of $<30 \mathrm{ml}$ per hour, and a heart rate of $\geqslant 60$ beats per minute). The hemodynamic criteria were a cardiac index of no more than 2.2 liters per minute per square meter of body-surface area and a pulmonary-capillary wedge pressure of at least $15 \mathrm{~mm} \mathrm{Hg}$. Pulmonary-artery catheterization was not required before randomization for patients with anterior infarction and evidence of pulmonary congestion on radiography. The onset of shock had to be within 36 hours of infarction, and randomization had to occur as soon as possible and no more than 12 hours after the diagnosis of shock. The clinical exclusion criteria ${ }^{24}$ were severe systemic illness, mechanical or other cause of shock, severe valvular disease, dilated cardiomyopathy, the inability of care givers to gain access for catheterization, and unsuitability for revascularization.

\section{Statistical Analysis}

Thirty-day mortality was monitored by the trial statistician using a continuous sequential design ${ }^{25}$ and was reviewed monthly by the chair of the data and safety monitoring board. It was calculated that a sample of 328 patients would give the study 90 percent power with an overall type I error rate of 0.05 to detect a 20 percent absolute difference between groups based on two sets of hypothesized mortality rates: 30 percent versus 50 percent (requiring 328 patients), and 55 percent versus 75 percent (requiring 312 patients). The final trial enrolled 302 patients, which resulted in a power of 88 to 89 percent to detect an absolute difference of 20 percent between the groups as described above, with the use of continuous sequential monitoring.

Thirty-day mortality as well as other categorical characteristics of the patients in the two groups were compared by Fisher's exact test. Group differences in continuous factors were compared by Student's t-test and the Wilcoxon rank-sum test. A test of interaction (the Breslow-Day test of homogeneity of odds ratios) was used to identify factors that were associated with a differential treatment effect within a subgroup. ${ }^{26}$ Ten prespecified subgroups with fixed characteristics determined before randomization were examined. The subgroups were based on sex, age $(<75$ vs. $\geqslant 75$ years), type of admission (direct vs. transfer), time of shock (early vs. late, according to three definitions), eligibility or ineligibility for thrombolytic therapy, location of the site (U.S. vs. non-U.S.), anterior infarction (presence vs. absence), prior infarction (presence vs. absence), hypertension (presence vs. absence), and diabetes mellitus (presence vs. absence). Descriptive statistics are presented as means $\pm S D$ or as percentages.

Kaplan-Meier curves were generated for the analysis of time to death, and logistic regression was used for the adjustment of 30day mortality for covariates. The vital status of four heart-transplant recipients was analyzed without regard to the date of transplantation. All $\mathrm{P}$ values are two-sided and are unadjusted for interim examinations of the data. Analyses were based on all randomized patients according to the intention-to-treat principle unless otherwise noted. Analyses were conducted with Statistical Analysis System ${ }^{27}$ and S-Plus ${ }^{28}$ software.

\section{RESULTS}

\section{Patients}

\section{Comparability of Study and Registry Cohorts}

A total of 1492 patients with suspected shock were screened, and more than 75 percent of the eligible patients underwent randomization. Of the 1190 nonrandomized (registry) patients, 1107 were ineligible. Of the ineligible patients, 52 percent did not meet all the inclusion criteria; these patients had a 56 percent in-hospital mortality rate. The remaining 48 percent met one or more exclusion criteria; these patients had a 66 percent in-hospital mortality rate. Seventy-four percent of the nonrandomized patients ( 884 patients) were classified as having predominant left ventricular failure. The 302 randomized patients were similar to those 884 patients except as noted in Table 1. Eighty-three patients were medically eligible for the trial but were not randomized. They were older than the randomized patients $(\mathrm{P}=0.02)$ and had higher mortality $(\mathrm{P}=0.003)$. Many 
Table 1. Characteristics of Randomized and Nonrandomized Patients.

\begin{tabular}{|c|c|c|c|c|}
\hline \multirow[t]{2}{*}{ Characteristic } & \multirow[t]{2}{*}{$\begin{array}{c}\text { RANDOMIZEd } \\
\text { PATIENTS } \\
\text { (N=302) }\end{array}$} & \multicolumn{2}{|c|}{$\begin{array}{c}\text { NonRANDOMIZED } \\
\text { (REGISTRY) PATIENTS }\end{array}$} & \multirow[t]{2}{*}{$\begin{array}{c}P \\
V_{A L U E}+\end{array}$} \\
\hline & & $\begin{array}{c}\text { PATIENTS } \\
\text { WITH LEFT } \\
\text { VENTRICULAR } \\
\text { FAILURE } \\
(\mathrm{N}=884)\end{array}$ & $\begin{array}{c}\text { ELIGIBLE } \\
\text { PATIENTS* } \\
(\mathrm{N}=83)\end{array}$ & \\
\hline Mean $( \pm S D)$ age - yr & $65.8 \pm 10.4$ & $68.5 \pm 12.1$ & $69.0 \pm 12.2$ & $<0.001$ \\
\hline Male sex $-\%$ & 67.9 & 63.6 & 63.9 & 0.19 \\
\hline White race, non-Hispanic - \% & 75.5 & 83.7 & 81.9 & 0.002 \\
\hline Transfer admission — \% & 55.3 & 43.2 & 45.8 & $<0.001$ \\
\hline Prior myocardial infarction — $\%$ & 32.5 & 40.1 & 44.2 & 0.02 \\
\hline Hypertension — \% & 46.3 & 51.7 & 59.2 & 0.12 \\
\hline Diabetes mellitus — \% & 31.1 & 32.8 & 38.0 & 0.62 \\
\hline Congestive heart failure - \% & 6.1 & 19.8 & 19.2 & $<0.001$ \\
\hline Prior coronary-artery bypass grafting - $\%$ & 6.0 & 10.1 & 7.5 & 0.04 \\
\hline Prior angioplasty — $\%$ & 7.1 & 6.7 & 7.5 & 0.89 \\
\hline Anterior index myocardial infarction — \% & 59.8 & 58.8 & 67.1 & 0.78 \\
\hline Death - \% & 51.3 & 60.8 & 69.9 & 0.005 \\
\hline Death after angioplasty — \% (no.)\$ & $40.0(105)$ & $46.2(290)$ & $61.8(34)$ & 0.30 \\
\hline $\begin{array}{l}\text { Death after coronary-artery bypass graft } \\
\quad \% \%(\text { no. }) \mathbb{S}\end{array}$ & $40.5(74)$ & $27.9(136)$ & $38.5(13)$ & 0.07 \\
\hline
\end{tabular}

*Eligible nonrandomized patients were a subgroup of the nonrandomized patients with left ventricular failure.

$\dagger \mathrm{P}$ values are for the comparison between randomized patients and all registry patients with left ventricular failure.

$\ddagger$ Thirty-day mortality is shown for randomized patients, and in-hospital mortality for nonrandomized patients.

$\$$ The numbers in parentheses are the numbers of patients who underwent angioplasty or coronaryartery bypass grafting. The randomized group includes patients assigned to emergency revascularization and patients assigned to initial medical stabilization. Angioplasty and surgery performed at any time during the hospitalization are included for the randomized and nonrandomized cohorts. The mortality rates for all nonrandomized patients with left ventricular failure who underwent angioplasty, or surgery, or both within 24 hours after the diagnosis of shock (timing that is similar to that for the patients assigned to emergency revascularization, whose outcomes are presented in the Results section) were 47 percent ( 216 patients) and 38 percent ( 52 patients), respectively.

of these patients were not randomized because they died soon after hospital admission.

\section{Comparability of Treatment Groups}

The study cohort consisted of 152 patients assigned to revascularization and 150 assigned to medical treatment. One hundred seventy-five patients ( 58 percent) were treated in the United States, 66 (22 percent) in Canada, and 61 (20 percent) in other countries. The two treatment groups were well balanced (Table 2$)$. The mean $( \pm S D)$ age was $66 \pm 10$ years, 32 percent were women, and 55 percent had been transferred from another hospital. The median time from the onset of infarction to shock was 5.6 hours. The patients in the two groups had similar medical histories, except that more patients assigned to medical therapy had previously undergone bypass surgery ( 10 percent vs. 2 percent, $\mathrm{P}=0.003$ ). Hemodynamic measurements were most often obtained while the patients were receiving support and demonstrated profound abnormalities confirming cardiogenic shock.

\section{Compliance with the Protocol}

Overall compliance with the protocol was excellent: 97 percent of the patients assigned to revascularization underwent early coronary angiography, and 87 percent underwent revascularization. Of the 20 patients assigned to revascularization who did not undergo a revascularization attempt (13.2 percent), 5 died before coronary angiography could be performed. An additional 10 patients ( 6.6 percent) underwent revascularization more than 6 hours after randomization ( 5 patients at 6 to 8 hours and 5 at 23 hours or more after randomization). In the group assigned to medical therapy, the rate of crossovers that were in violation of the study protocol was only 2.7 percent (four 
Table 2. Characteristics of the Study Patients According to Treatment Group.*

\begin{tabular}{|c|c|c|}
\hline Characteristic & $\begin{array}{l}\text { REVAscularizATION } \\
(\mathbf{N}=152)\end{array}$ & $\begin{array}{l}\text { Medical THERAPY } \\
(\mathbf{N}=\mathbf{1 5 0})\end{array}$ \\
\hline Age (yr) & $65.5 \pm 10.0$ & $66.2 \pm 10.9$ \\
\hline Female sex $(\%)$ & 36.8 & 27.3 \\
\hline White race, non-Hispanic (\%) & 72.4 & 78.7 \\
\hline Prior MI $(\%)$ & 29.6 & 35.3 \\
\hline Hypertension (\%) & 49.0 & 43.5 \\
\hline Diabetes mellitus (\%) & 34.2 & 27.9 \\
\hline Congestive heart failure (\%) & 4.0 & 8.2 \\
\hline Renal insufficiency (\%) & 4.6 & 6.9 \\
\hline Prior coronary-artery bypass grafting (\%) & 2.0 & 10.0 \\
\hline Prior angioplasty (\%) & 6.7 & 7.4 \\
\hline Cigarette smoking (\%) & 52.6 & 56.8 \\
\hline Eligible for thrombolytic therapy $(\%) \dagger$ & 94.1 & 94.6 \\
\hline Transfer admission (\%) & 55.3 & 55.3 \\
\hline Anterior index MI (\%) & 63.6 & 57.4 \\
\hline Highest total creatine kinase (IU/liter) & $3068(1322-6350)$ & $3464(1543-5411)$ \\
\hline Median time from MI to shock (hr) & $5.0(2.2-12.0)$ & $6.2(2.4-15.5)$ \\
\hline Median time from MI to randomization (hr) & $11.0(5.9-19.4)$ & $12.0(6.3-21.8)$ \\
\hline$<6 \mathrm{hr}$ from MI to randomization (\%) & 25.0 & 23.7 \\
\hline Lowest systolic blood pressure $(\mathrm{mm} \mathrm{Hg}) \ddagger$ & $66.4 \pm 14.3$ & $69.8 \pm 11.3$ \\
\hline Systolic blood pressure $(\mathrm{mm} \mathrm{Hg}) \mathfrak{S}$ & $89.0 \pm 22.8$ & $86.5 \pm 17.4$ \\
\hline Diastolic blood pressure $(\mathrm{mm} \mathrm{Hg}) \mathfrak{S}$ & $53.9 \pm 16.8$ & $55.1 \pm 13.6$ \\
\hline Heart rate (beats $/ \mathrm{min}) \mathbb{S}$ & $103.3 \pm 22.0$ & $100.1 \pm 22.7$ \\
\hline Pulmonary-capillary wedge pressure $(\mathrm{mm} \mathrm{Hg}) \mathfrak{\$} \mathbb{I}$ & $24.2 \pm 7.1$ & $24.3 \pm 7.7$ \\
\hline Cardiac index $\left(\right.$ liters $\left./ \mathrm{min} / \mathrm{m}^{2}\right) \boldsymbol{\$} \|$ & $1.8 \pm 0.7$ & $1.7 \pm 0.5$ \\
\hline Left ventricular ejection fraction $(\%)^{* *}$ & $29.1 \pm 10.6$ & $32.5 \pm 13.9$ \\
\hline $\begin{array}{l}\text { Number of diseased vessels }(\%) \dagger \dagger \\
\leqslant 1 \\
2 \\
3\end{array}$ & $\begin{array}{l}14.0 \\
21.7 \\
64.3\end{array}$ & $\begin{array}{l}11.5 \\
24.0 \\
64.6\end{array}$ \\
\hline Left main coronary artery disease $(\%) \ddagger \ddagger$ & 23.4 & 17.5 \\
\hline
\end{tabular}

*Plus-minus values are means \pm SD. Values in parentheses denote the interquartile range. MI denotes myocardial infarction.

†These patients had no absolute contraindications to thrombolytic therapy.

$\ddagger$ Values are based on 109 patients in the revascularization group and 106 in the medical-therapy group.

\$Values were most often recorded while the patient was receiving support.

IValues are based on 138 patients in the revascularization group and 144 in the medical-therapy group.

\|Values are based on 131 patients in the revascularization group and 140 in the medical-therapy group. Values are given in liters per minute per square meter of body-surface area.

${ }^{* *}$ Measurements were obtained from the left ventriculogram. Values are based on 46 patients in the revascularization group and 49 in the medical-therapy group.

$\dagger †$ Values are based on 143 patients in the revascularization group and 96 in the medical-therapy group. Two patients in the revascularization group and three patients in the medical-therapy group had no stenosis of 50 percent or greater.

$\ddagger \ddagger$ Values are based on 141 patients in the revascularization group and 97 in the medical-therapy group.

patients), representing revascularization attempts less than 54 hours after randomization. In addition, there were two protocol-allowed revascularization attempts ( 1.3 percent), one for refractory postinfarction angina and one for left ventricular rupture. Delayed revascularization was attempted in 32 patients assigned to medical treatment ( 21.3 percent).
After randomization, eight patients (five assigned to revascularization and three assigned to medical therapy) were determined to have shock due to a process other than primary left ventricular dysfunction. Four of these had acute severe mitral regurgitation, and four had aortic dissection, tamponade, or both. Ten randomized patients were found to be 
ineligible, but for minor reasons: three of them had nonqualifying myocardial infarctions, hemodynamic confirmation of shock was not obtained in five, and three were assigned to treatment more than 12 hours after shock (one of these patients also had a nonqualifying myocardial infarction).

\section{Treatment}

Except for treatment recommended or required according to the protocol for the two study groups (i.e., administration of thrombolytic therapy and revascularization), treatment was similar in the two groups (Table 3). ${ }^{24}$ Among the patients assigned to revascularization, angioplasty accounted for 64 percent of the first revascularization attempts and surgery for 36 percent. Patients undergoing surgery were more likely than patients undergoing angioplasty to have left main coronary artery disease $(40$ percent vs. 14 percent, $\mathrm{P}<0.001)$ and three-vessel coronary artery disease ( 79 percent vs. 60 percent, $\mathrm{P}=0.008$ ). These two groups of patients were similar in other characteristics. In the revascularization group, the median time from randomization to the first revascularization attempt was 0.9 hour for patients undergoing angioplasty and 2.7 hours for patients undergoing surgery. Nine patients assigned to revascularization underwent surgery after an attempted angioplasty. Mechanical ventilation was used more often in patients assigned to revascularization than in those assigned to medical therapy ( 88 percent vs. 78 percent, $\mathrm{P}=0.03$ ), probably in relation to concomitant surgery.

\section{0-Day Overall Mortality}

Seventy-one patients assigned to revascularization and 84 assigned to medical therapy died within 30 days after randomization (Table 4 ). The 30 -day mortality rates for the revascularization and medicaltherapy groups were 46.7 percent and 56.0 percent, respectively (difference between the groups, -9.3 percent; 95 percent confidence interval for the difference, -20.5 to 1.9 percent; $\mathrm{P}=0.11$ ). The relative difference was 17 percent (relative risk, 0.83 ; 95 percent confidence interval, 0.67 to 1.04 ). Covariate adjustment for minor group imbalances did not alter the main study finding $(\mathrm{P}=0.16)$. Figure 1 shows estimated 30-day survival. Patients assigned to revascularization had a high risk of death on days 1 and 2, whereas those assigned to medical therapy had a relatively constant risk of death over the first week. In the group assigned to revascularization, the 30 -day mortality was 45.3 percent among the 75 patients who underwent angioplasty alone and 42.1 percent among those who underwent surgery ( 57 patients, including 9 who underwent angioplasty before surgery).

Two alternative prespecified analyses of 30-day mortality were conducted. According to the first analysis, which excluded the 18 ineligible patients, the
Table 3. Treatment of the Study Patients.

\begin{tabular}{|c|c|c|}
\hline TreatMent & $\begin{array}{l}\text { REVASCULARIZATION } \\
\qquad(\mathrm{N}=152)\end{array}$ & $\begin{array}{c}\text { MEDICAL } \\
\text { THERAPY } \\
(\mathbf{N}=150)\end{array}$ \\
\hline $\begin{array}{l}\mathrm{CPR}, \mathrm{VT}, \text { or } \mathrm{VF} \text { before randomization } \\
(\%)^{*}\end{array}$ & 32.7 & 23.9 \\
\hline Thrombolytic therapy (\%) & 49.3 & 63.3 \\
\hline Inotropes or vasopressors (\%) & 99.3 & 98.6 \\
\hline Intraaortic balloon counterpulsation (\%) & 86.2 & 86.0 \\
\hline Pulmonary-artery catheterization (\%) & 93.4 & 96.0 \\
\hline Left ventricular assist device $(\%) \dagger$ & 3.6 & 0.9 \\
\hline Heart transplantation (\%) & 2.0 & 0.7 \\
\hline Coronary angiography (\%) & 96.7 & 66.7 \\
\hline Angioplasty (\%) & 54.6 & 14.0 \\
\hline Stent placed $\ddagger$ & 35.7 & 52.3 \\
\hline $\begin{array}{l}\text { Platelet glycoprotein } \mathrm{IIb} / \mathrm{IIIa} \\
\text { receptor antagonist } \$\end{array}$ & 41.7 & 25.0 \\
\hline Coronary-artery bypass grafting (\%) & 37.5 & 11.3 \\
\hline $\begin{array}{l}\text { Angioplasty or coronary-artery bypass } \\
\text { grafting }(\%)\end{array}$ & 86.8 & 25.3 \\
\hline $\begin{array}{l}\text { Median time from randomization to } \\
\text { revascularization }(\mathrm{hr}) \mathbb{I}\end{array}$ & $\begin{array}{c}1.4 \\
(0.6-2.8)\end{array}$ & $\begin{array}{c}102.8 \\
(79.0-162.0)\end{array}$ \\
\hline
\end{tabular}

${ }^{*} \mathrm{CPR}$ denotes cardiopulmonary resuscitation, VT sustained ventricular tachycardia, and VF sustained ventricular fibrillation. Patients could have had more than one of these factors. Values are based on 113 patients in the revascularization group and 113 in the medical-therapy group.

†Values are based on 111 patients in the revascularization group and 110 in the medical-therapy group.

$\ddagger$ The rate of stent use (for any lesion) was 0 percent in 1993-1994, 19 percent in 1995-1996, and 74 percent in 1997-1998.

$\$$ The rate of use of a platelet glycoprotein IIb/IIIa receptor antagonist was 0 percent in 1993-1994, 27 percent in 1995-1996 (estimated), and 59 percent in 1997-1998. Values are based on 60 patients in the revascularization group and 20 in the medical-therapy group.

IValues in parentheses indicate the interquartile range.

30-day mortality rate was 54.9 percent for the 142 patients assigned to revascularization and 45.1 percent for the 142 patients assigned to medical therapy, for an absolute difference of 9.8 percent. The second analysis (not performed according to the intentionto-treat principle) was based on 122 patients assigned to revascularization who underwent revascularization within six hours after randomization and 144 patients assigned to medical therapy who had late or no revascularization. This analysis found 30day mortality rates of 45.9 percent and 56.9 percent, respectively, for an absolute difference of 11.0 percent.

\section{Six-Month Overall Mortality}

Overall mortality six months after infarction (Table 4) was lower in the group assigned to revascularization than in the group assigned to medical therapy (50.3 percent vs. 63.1 percent; 95 percent confidence interval for the difference, -23.2 to -0.9 percent; $\mathrm{P}=0.027$ ). Five patients assigned to revascularization and 10 assigned to medical therapy died 
The New England Journal of Medicine

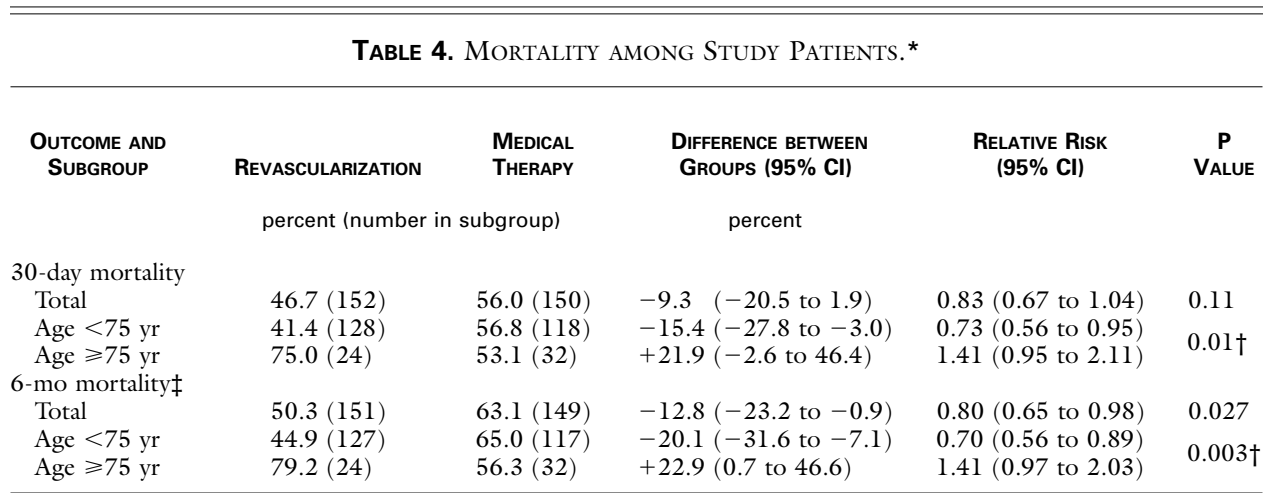

${ }^{*} \mathrm{CI}$ denotes confidence interval.

†Appropriate subgroup-analysis $\mathrm{P}$ values (for the interaction between treatment and the subgroup variable) are shown. Univariate $\mathrm{P}$ values for the comparison between treatments within subgroups were as follows: for 30-day mortality, $\mathrm{P}=0.02$ for patients $<75$ years of age and $\mathrm{P}=0.16$ for those $\geqslant 75$ years of age; and for 6 -month mortality, $\mathrm{P}=0.002$ for patients $<75$ years of age and $\mathrm{P}=0.09$ for those $\geqslant 75$ years of age.

$\ddagger$ The data are based on 300 patients; 2 patients ( 0.7 percent) were lost to follow-up.

between 30 days and 6 months after randomization. Preliminary 12 -month data indicate persistently lower mortality in the group assigned to revascularization.

\section{Subgroup Analyses}

In the 10 prespecified subgroup analyses of 30 day mortality, 2 variables had a significant interaction with treatment: age and history of myocardial infarction (Table 4 ). The only subgroup variable that interacted significantly with treatment both at 30 days and at 6 months was age $(\mathrm{P}=0.01$ and $\mathrm{P}=0.003$, respectively). Figure 2 shows the relative-risk estimates and 95 percent confidence intervals from the 10 prespecified subgroup analyses. The interaction between

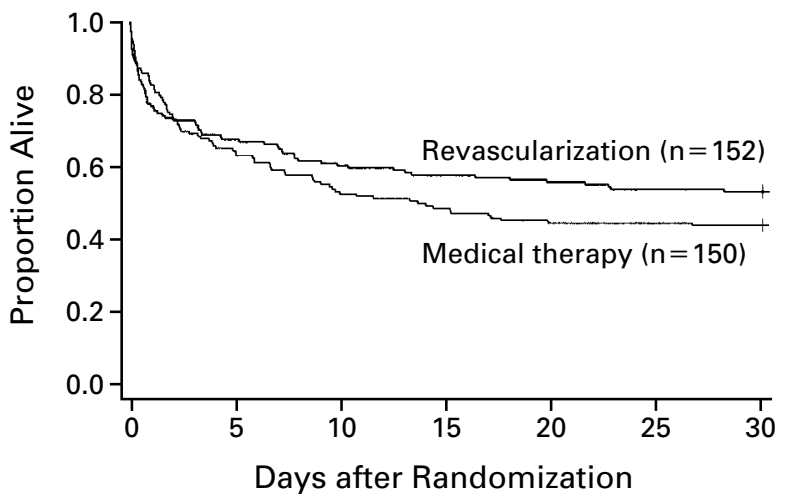

Figure 1. Overall 30-Day Survival in the Study.

The 30-day survival rate was 53.3 percent for patients assigned to revascularization and 44.0 percent for those assigned to medical therapy. treatment group and history of myocardial infarction, which was significant at 30 days $(\mathrm{P}=0.02)$, was not significant at 6 months $(\mathrm{P}=0.15)$.

\section{Success of Angioplasty}

A successful angioplasty met three criteria: no more than 50 percent post-intervention stenosis, improvement of at least 20 percent in the degree of stenosis, and a flow of Thrombolysis in Myocardial Infarction (TIMI) grade II or III. ${ }^{29}$ The rates of success of culprit-vessel angioplasty were 77 percent for the group assigned to revascularization (81 patients) and 80 percent for the group assigned to medical therapy (20 patients). Among patients assigned to revascularization, successful angioplasty was associated with lower 30 -day mortality (38 percent for patients with successful angioplasty vs. 79 percent for those with unsuccessful angioplasty, $\mathrm{P}=0.003$ ). The use of stents and platelet glycoprotein IIb/IIIa receptor antagonists increased over time (Table 3). Among the 45 patients assigned to revascularization who underwent angioplasty in 1997 or 1998, 19 received both a stent and a platelet glycoprotein IIb/IIIa receptor antagonist, 15 received a stent only, 7 received a platelet glycoprotein IIb/IIIa receptor antagonist only, and 4 received neither. The respective mortality rates were $37,33,71$, and 0 percent. These outcomes are similar to the 39 percent mortality rate among the 23 patients undergoing angioplasty who did not receive stents or platelet glycoprotein IIb/IIIa receptor antagonists in 1993 and 1994.

\section{Adverse Events}

The rates of adverse events were similar for the patients assigned to revascularization and those assigned 


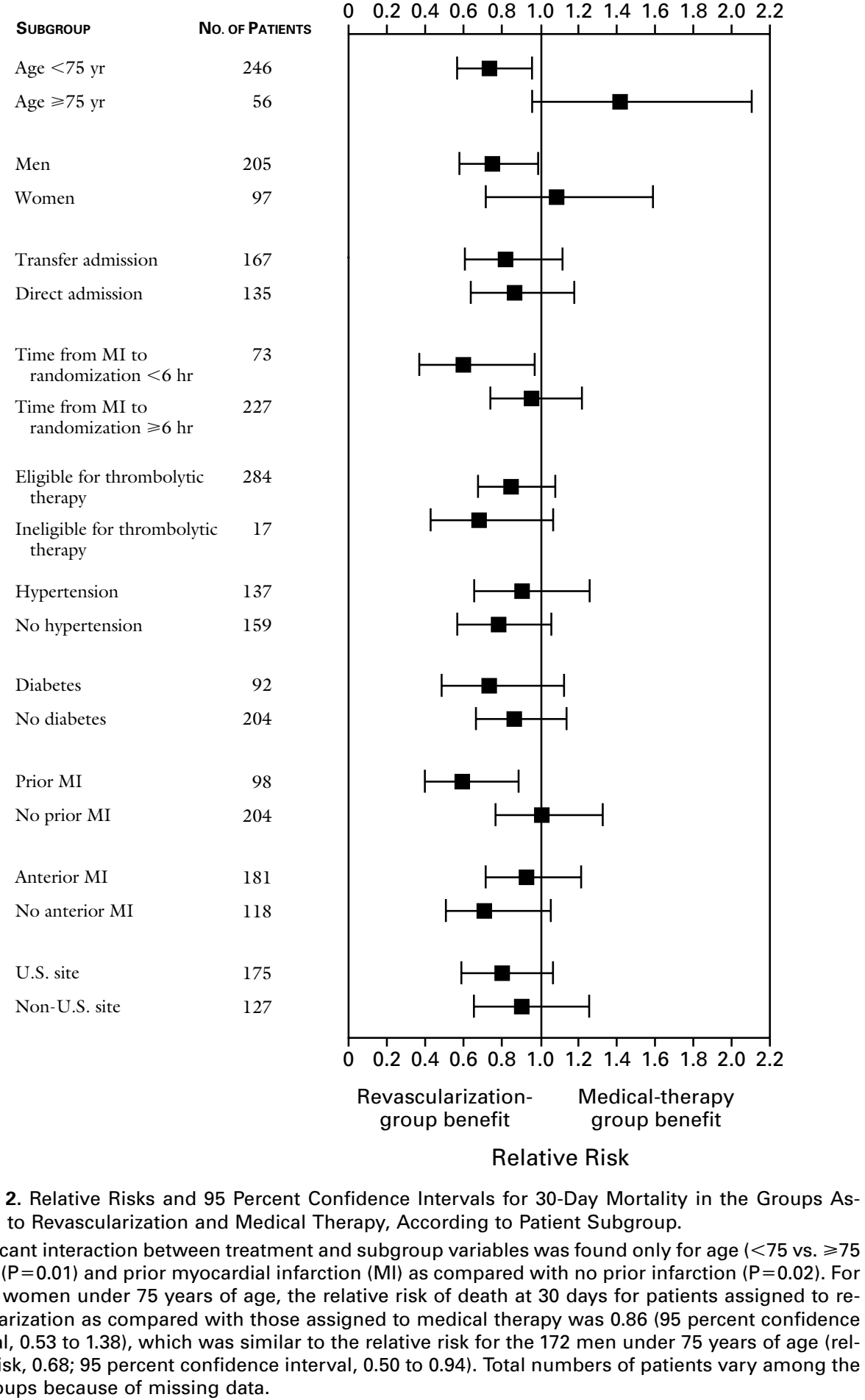


to medical therapy, with the exception of acute renal failure, defined by a serum creatinine level above 3.0 mg per deciliter (265 $\mu \mathrm{mol}$ per liter), which occurred in 13 percent of the patients assigned to revascularization and 24 percent of those assigned to medical therapy $(\mathrm{P}=0.03)$. The overall rate of severe hemorrhage was 28 percent, and intracranial hemorrhage occurred in 0.7 percent (two patients assigned to medical therapy). Five patients assigned to revascularization and one assigned to medical therapy had nonhemorrhagic cerebrovascular accidents. Sepsis was suspected in 19 percent, and peripheral vascular occlusion occurred in 11 percent.

\section{DISCUSSION}

This study was a randomized trial evaluating early revascularization therapy to reduce the high mortality rate associated with cardiogenic shock complicating acute myocardial infarction. The primary end point, overall mortality at 30 days, was not significantly reduced by early revascularization. However, a benefit in terms of mortality was apparent six months after infarction.

We studied patients who had cardiogenic shock due to left ventricular dysfunction after acute infarction associated with ST-segment elevation or new left bundle-branch block. A strategy of emergency revascularization - involving early coronary angiography, followed by coronary angioplasty, coronaryartery bypass graft surgery, or both - was compared with a strategy of initial stabilization with intensive medical therapy, followed by delayed revascularization if it was clinically indicated. The trial was designed in the early 1990s in the context of a high mortality rate among patients with cardiogenic shock, as well as reported reductions in mortality of 30 percent or more among patients undergoing angioplasty or coronary-artery surgery in nonrandomized series. $^{5-15}$ These large reductions clearly reflected bias related to selection for treatment.

The 9 percent absolute difference in 30-day mortality between the two groups was less than the prespecified 20 percent difference. However, we observed a larger difference between the groups in mortality beyond 30 days. The secondary end point, six-month mortality, was 13 percentage points lower for the group assigned to emergency revascularization. This apparently increasing benefit over time is in distinct contrast to the converging survival curves for patients with infarction and no shock who are treated with primary angioplasty and those who are treated with thrombolytic therapy. ${ }^{30,31}$ It is similar to the divergence in the two-year survival curves for patients with normal coronary flow and those with abnormal flow in the Global Utilization of Streptokinase and t-PA for Occluded Coronary Arteries trial. ${ }^{32}$

Analysis of interactions between treatment effect and prespecified variables suggested that the greatest benefit may have been in the subgroup of patients less than 75 years of age who underwent early revascularization (81 percent of study patients were younger than 75 years of age). However, the subgroup analyses should be interpreted cautiously, given the multiple testing and the null results for the primary end point.

The 30-day mortality rate of 56 percent in the group assigned to medical therapy is relatively low for patients of their age and hemodynamic profile. This may be due to the selection of healthier patients who survived long enough to be assigned to treatment, the aggressive therapy they received, or both. Intraaortic balloon counterpulsation and thrombolysis were frequently used, and 25 percent of the patients assigned to medical therapy underwent revascularization during hospitalization for shock. Thrombus dissolution was facilitated by balloon counterpulsation in a dog model of hypotension. ${ }^{33}$ Nonrandomized studies report 33 to 45 percent mortality among patients selected for balloon counterpulsation and thrombolysis, often followed by late revascularization. ${ }^{34,35}$

\section{Success of Revascularization}

The reported success rates of angioplasty in patients with acute myocardial infarction are lower for patients with shock than for those without shock. ${ }^{30,36}$ Studies of pooled data on 730 patients found a 78 percent success rate, a result similar to ours. ${ }^{37}$ Success was less stringently defined in our study, however, and previous series did not use core-laboratory readings. Although patients in the last two years of the study who received stents, platelet glycoprotein IIb/IIIa receptor antagonists, or both had the same outcome as patients in earlier years who did not receive these interventions, it is possible that higher rates of use would result in better outcomes. Despite the fact that the patients in our study who underwent early coronary-artery bypass grafting had more severe coronary disease than the patients who underwent early angioplasty, their mortality rates were similar.

\section{Comparison with Prior Studies}

The Swiss Multicenter Angioplasty for Shock trial compared angioplasty with conventional therapy and was terminated because of inadequate enrollment of patients. ${ }^{19}$ The higher mortality rates in that trial $(69$ percent among patients assigned to emergency revascularization and 78 percent among patients assigned to medical therapy) than in our trial were consistent with the requirement that patients have no response to initial supportive measures. The 9 percent absolute difference between the groups in 30-day mortality was the same as that in our study.

The mortality rate among patients assigned to revascularization who underwent angioplasty in our study is similar to the 44 percent rate among 1167 patients in 24 other studies. The mortality rate is re- 
lated to the success of restoring flow in the infarcted vessels. ${ }^{37}$ The mortality rate was 36 percent among 830 patients in 26 studies who underwent bypass surgery at any time during hospitalization for shock, often late after infarction, when shock had resolved. ${ }^{37}$ This rate is similar to the mortality rate among our patients assigned to revascularization who underwent early surgery.

\section{Generalizability of the Results}

Data from our concomitant 1190-patient registry demonstrate that our randomized cohort was representative of patients with shock caused by predominant left ventricular failure. There were small differences in base-line characteristics, which were probably related to the association of these variables with exclusion criteria, such as cardiomyopathy. The outcome of angioplasty and surgery was similar in registry and study patients, suggesting that the healthiest patients were not selectively included in or excluded from the trial. The high rate of randomization of medically eligible patients suggests that the results can be extrapolated to patients with this condition who are treated in centers that have experience with revascularization procedures.

\section{Limitations}

Our trial was designed to detect a 20 percent absolute difference in mortality at 30 days and had inadequate power to detect a smaller difference. More than 1000 patients would have been required to test, with 90 percent power, the hypothesis that early revascularization reduces 30 -day mortality by 9 percentage points. The small number of patients who underwent randomization within hours after infarction precludes conclusions regarding a potentially greater benefit of very early revascularization. Similarly, the small number of elderly patients studied precludes conclusions about the most effective treatment in this age group.

\section{Conclusions}

At 30 days there was no significant overall benefit of early revascularization for patients with myocardial infarction associated with ST-segment elevation or new left bundle-branch block who had cardiogenic shock due to left ventricular dysfunction. However, early revascularization resulted in lower mortality from all causes at six months. Hence, we recommend that early revascularization be strongly considered for patients with acute myocardial infarction complicated by cardiogenic shock.

Preliminary data were presented at the American College of Cardiology meeting, New Orleans, March 7-10, 1999.

Supported by grants from the National Heart, Lung, and Blood Institute (R01-HL50020-018Z and R01-HL49970) and by a grant-in-aid from the American Heart Association, New York Affiliate, in the early phase of the study.
We are indebted to the study investigators and coordinators for their dedication and performance; to Julia Nisbet-Brown and John Lim for their efforts; to Venu Menon, M.D., for his assistance; and to Richard Fuchs, M.D., for his thoughtful guidance and his editorial assistance.

\section{APPENDIX}

The following are the committee members, principal investigators, and study coordinators of the SHOCK trial: Executive Committee: J. Hoch man, study chair; T. LeJemtel, cochair; P. Aylward, J. Boland, J. Col, O.W. Isom, S. McKinlay, M. Picard, T. Sanborn, L. Sleeper, H. White, and P. Desvigne-Nickens (ex officio). Publications Committee: $H$. White, Chair; J. Abel, J. Hochman, T. LeJemtel, L. Sleeper, and J. Webb. Data and Safety Monitoring Board: E. Braunwald, chair; F. Loop, C. McCarthy, N. Scott, D. Williams, and J. Wittes. Clinical Centers (according to enrollment ranking): J. Webb, C. Thompson, J. Abel, and E. Buller, St. Paul's Hospital (Vancouver, B.C., Canada); J.D. Talley, J. Harrell, M. Dearen, M. Rawert, and R. Pacheco, University of Arkansas for Medical Sciences (Little Rock); J. Slater, A. Palazzo, R. Leber, C. Connery, and D. Tormey, St. Luke's-Roosevelt Hospital Center (New York); A. Jacobs, R. Shemin, and M. Mazur, Boston University Medical Center (Boston); C. Buller, K. Gin, E. Jamieson, and R. Fox, Vancouver General Hospital (Vancouver, B.C., Canada); D.H. Miller, T. Sanborn, R. Campagna, O.W. Isom, and S. Hosat, New York Hospital-Cornell Medical Center (New York); H. White, J. French, K. Graham, and B. Williams, Green Lane Hospital (Auckland, New Zealand); M. Menegus, M. Greenberg, R. Brodman, and B. Levine, Montefiore Medical Center-Albert Einstein College of Medicine (Bronx, N.Y.); J. Boland, R. Limet, S. Pourbaix, P. Baumans, and M. Massoz, Centre Hospitalier Regional Citadelle (Liege, Belgium); J. Col, R. Dion, and R. Lauwers, Cliniques Universitaires St. Luc (Brussels, Belgium); R. Forman, E.S. Monrad, D. Sisto, M. Galvao, and M. Jones, J.D. Weiler Hospital of the Albert Einstein College of Medicine (Bronx, N.Y.); J. Ambrose, S. Sharma, T. Cocke, J. Galls, D. Ratner, and E. Brown, Mount Sinai Medical Center (New York); R. Steingart and S. Parker, Winthrop University Hospital (Mineola, N.Y.); S.C. Wong, G.M. Gustafson, S. Papadakos, S. Lang, M. Brown, and M.C. Boileau, New York Hospital Medical Center of Queens (Flushing, N.Y.); V. Dzavik, W. Tymchak, A. Koshal, C. Kee, and L. Harris, University of Alberta Hospital (Edmonton, Alta., Canada); M. Porway, J. Flack, and B. Burkott, Baystate Medical Center (Springfield, Mass.); A. Moreyra, S. Palmeri, A. Spotnitz, and M. Hosler, University of Medicine and Dentistry of New Jersey-Robert Wood Johnson Medical School (New Brunswick); P. Aylward, J. Knight, and C. Thomas, Flinders Medical Centre (Adelaide, S.A., Australia); J. Dens, F. Van de Werf, P. Sergeants, and C. Luys, Gasthuisberg University Hospital (Leuven, Belgium); K. Baran, P. Koller, P. Filkins, and C. Iacarella, St. Paul Heart Clinic (St. Paul, Minn.); M. Pfisterer, P. Buser, and M. Weinbacher, University Hospital Basel (Basel, Switzerland); L.D. Hillis, J. Cigarroa, and J. Kissee, University of Texas Southwestern Medical Center (Dallas); S. Graham, S. Raza, and J. Celano, Buffalo General Hospital (Buffalo, N.Y.); J. Brinker and V. Coombs, Johns Hopkins Hospital (Baltimore); E. Ribeiro, A.C. Carvalho, C. Rodrigues Alves, and A. Petrizzo, Paulista School of Medicine (São Paulo, Brazil); J. Dervan, W. Lawson, and P. Montes, State University of New York at Stony Brook (Stony Brook); D. Faxon and R. Singh, University of Southern California Medical Center (Los Angeles); P.R. Paulsen and E. Miller, Hennepin County Medical Center (Minneapolis); B. Weiner and M. Borbone, University of Massachusetts (Worcester); E. Bates, University of Michigan Medical Center (Ann Arbor). Angiography Core Laboratory: T. Sanborn (director), G. Bergman, M.A. Parikh, and A. Spokojny, New York Hospital-Cornell Medical Center (New York). Echocardiography Core Laboratory: M.H. Picard (director), Massachusetts General Hospital (Boston); R. Davidoff and L. Mendes, Boston University Medical Center (Boston). Clinical Coordinating Center: J.S. Hochman, T.H. LeJemtel, and E. Godfrey, St. Luke's-Roosevelt Hospital Center (New York). Data Coordinating Center: S.M. McKinlay, L.A. Sleeper, J. Lim, and J. Nisbet-Brown, New England Research Institutes (Watertown,

Mass.). Program Administration: P. Desvigne-Nickens, National Heart, Lung, and Blood Institute (Bethesda, Md.).

\section{REFERENCES}

1. Goldberg RJ, Gore JM, Alpert JS, et al. Cardiogenic shock after acute myocardial infarction: incidence and mortality from a community-wide perspective, 1975 to 1988. N Engl J Med 1991;325:1117-22.

2. Killip T III, Kimball JT. Treatment of myocardial infarction in a coronary care unit: a two year experience with 250 patients. Am J Cardiol 1967; 20:457-64.

3. Holmes DR Jr, Bates ER, Kleiman NS, et al. Contemporary reperfusion 
therapy for cardiogenic shock: the GUSTO-I trial experience. J Am Coll Cardiol 1995;26:668-74.

4. Becker RC, Gore JM, Lambrew C, et al. A composite view of cardiac rupture in the United States National Registry of Myocardial Infarction. J Am Coll Cardiol 1996;27:1321-6.

5. Lee L, Bates ER, Pitt B, Walton JA, Laufer N, O’Neill WW. Percutaneous transluminal coronary angioplasty improves survival in acute myocardial infarction complicated by cardiogenic shock. Circulation 1988;78 1345-51.

6. Verna E, Repetto S, Boscarini M, Ghezzi I, Binaghi G. Emergency coronary angioplasty in patients with severe left ventricular dysfunction or cardiogenic shock after acute myocardial infarction. Eur Heart J 1989;10:958-66. 7. Moosvi AR, Khaja F, Villanueva L, Gheorghiade M, Douthat L, Goldstein S. Early revascularization improves survival in cardiogenic shock complicating acute myocardial infarction. J Am Coll Cardiol 1992;19:907-14. 8. Yamamoto H, Yahashi Y, Oka Y, et al. Efficacy of percutaneous transluminal coronary angioplasty in patients with acute myocardial infarction complicated by cardiogenic shock. Jpn Circ J 1992;56:815-21.

9. Hibbard MD, Holmes DR Jr, Bailey KR, Reeder GS, Bresnahan JF,

Gersh BJ. Percutaneous transluminal coronary angioplasty in patients with cardiogenic shock. J Am Coll Cardiol 1992;19:639-46.

10. Guyton RA, Arcidi JM Jr, Langford DA, Morris DC, Lieberman HA Hatcher CR Jr. Emergency coronary bypass for cardiogenic shock. Circulation 1987;76:Suppl V:V-22-V-27.

11. Bolooki $\mathrm{H}$. Emergency cardiac procedures in patients in cardiogenic shock due to complications of coronary artery disease. Circulation 1989; 76:Suppl II:II-37-II-48.

12. Kirklin JK, Blackstone $\mathrm{EH}$, Zorn GL Jr, et al. Intermediate-term results of coronary artery bypass grafting for acute myocardial infarction. Circulation 1985;72:Suppl II:II-175-II-178.

13. Subramanian VA, Roberts AJ, Zema MJ, et al. Cardiogenic shock following acute myocardial infarction: late function results after emergency cardiac surgery. N Y State J Med 1980;80:947-52

14. DeWood MA, Notske RN, Hensley GR, et al. Intraaortic balloon counterpulsation with and without reperfusion for myocardial infarction shock. Circulation 1980;61:1105-12.

15. Dunkman WB, Leinbach RC, Buckley MJ, et al. Clinical and hemodynamic results of intraaortic balloon pumping and surgery for cardiogenic shock. Circulation 1972;46:465-77.

16. Antoniucci D, Valenti R, Santoro GM, et al. Systematic direct angioplasty and stent-supported direct angioplasty therapy for cardiogenic shock complicating acute myocardial infarction: in-hospital and long-term survival. J Am Coll Cardiol 1998;31:294-300.

17. Himbert D, Juliard JM, Steg PG, Karrillon GJ, Aumont MC, Gourgon R. Limits of reperfusion therapy for immediate cardiogenic shock complicating acute myocardial infarction. Am J Cardiol 1994;74:492-4.

18. Hochman JS, Boland J, Sleeper LA, et al. Current spectrum of cardiogenic shock and effect of early revascularization on mortality: results of an international registry. Circulation 1995;91:873-81.

19. Urban $P$, Stauffer JC, Bleed D, et al. A randomized evaluation of early revascularization to treat shock complicating acute myocardial infarction: the (Swiss) multicenter trial of angioplasty for shock - (S)MASH. Eur Heart J 1999;20:1030-8.

20. Tiefenbrunn AJ, Chandra NC, French WJ, Gore JM, Rogers WJ. Clinical experience with primary percutaneous transluminal coronary angioplasty compared with alteplase (recombinant tissue-type plasminogen activator) in patients with acute myocardial infarction: a report from the
Second National Registry of Myocardial Infarction (NRMI-2). J Am Coll Cardiol 1998;31:1240-5.

21. Berger PB, Holmes DR Jr, Stebbins AL, Bates ER, Califf RM, Topol

EJ. Impact of an aggressive invasive catheterization and revascularization strategy on mortality in patients with cardiogenic shock in the Global Utilization of Streptokinase and Tissue Plasminogen Activator for Occluded Coronary Arteries (GUSTO-I) trial: an observational study. Circulation 1997;96:122-7.

22. Menon V, Hochman JS, Holmes DR Jr, et al. Lack of progress in cardiogenic shock: lessons from the GUSTO trials. J Am Coll Cardiol 1998; 31:Suppl A:136A. abstract.

23. Hochman JS, Buller CE, Dzavik V, et al. Cardiogenic shock complicating acute myocardial infarction-etiologies, management, and outcome; overall results of the SHOCK Trial Registry. Circulation 1998;98:Suppl I: I-778. abstract.

24. Hochman JS, Sleeper LA, Godfrey E, et al. Should we emergently revascularize occluded coronaries for cardiogenic shock: an international ran domized trial of emergency PTCA/CABG — trial design. Am Heart J 1999;137:313-21

25. Armitage P. Restricted sequential procedures. Biometrika 1957;44:9-26. 26. Breslow NE, Day NE. Statistical methods in cancer research. Vol. 1 .

The analysis of case-control studies. Lyon, France: International Agency for Research on Cancer, 1980. (IARC scientific publications no. 32.) 27. SAS system for Windows, version 6.12. Cary, N.C.: SAS Institute, 1996 (software).

28. S-PLUS for Windows, version 3.3. Seattle: Statistical Sciences, 1995 (software).

29. Chesebro JH, Knatterud G, Roberts R, et al. Thrombolysis in Myocardial Infarction (TIMI) Trial, Phase I: a comparison between intravenous tissue plasminogen activator and intravenous streptokinase: clinical findings through hospital discharge. Circulation 1987;76:142-54.

30. The Global Use of Strategies to Open Occluded Coronary Arteries in Acute Coronary Syndromes (GUSTO IIb) Angioplasty Substudy Investigators. A clinical trial comparing primary coronary angioplasty with tissue plasminogen activator for acute myocardial infarction. N Engl J Med 1997; 336:1621-8. [Erratum, N Engl J Med 1997;337:287.]

31. Michels KB, Yusuf $S$. Does PTCA in acute myocardial infarction affect mortality and reinfarction rates? A quantitative overview (meta-analysis) of the randomized clinical trials. Circulation 1995;91:476-85.

32. Ross AM, Coyne KS, Moreyra E, et al. Extended mortality benefit of early postinfarction reperfusion. Circulation 1998;97:1549-56.

33. Prewitt RM, Gu S, Schick U, Ducas J. Intraaortic balloon counterpulsation enhances coronary thrombolysis induced by intravenous administration of a thrombolytic agent. J Am Coll Cardiol 1994;23:794-8.

34. Stomel R, Rasak M, Bates ER. Treatment strategies for acute myocardial infarction complicated by cardiogenic shock in a community hospital. Chest 1994;105:997-1002.

35. Barron HV, Pirzada SR, Lomnitz DJ, Every NR, Gore JM, Chou TM. Use of intra-aortic balloon counterpulsation in patients with acute myocardial infarction complicated by cardiogenic shock. J Am Coll Cardiol 1998; 31:Suppl A:135A. abstract.

36. Grines CL, Browne KF, Marco J, et al. A comparison of immediate angioplasty with thrombolytic therapy for acute myocardial infarction. N Engl J Med 1993;328:673-9.

37. Hochman JS, Gersh BJ. Acute myocardial infarction: complications. In: Topol EJ, ed. Textbook of cardiovascular medicine. Philadelphia: Lippincott-Raven, 1998:437-80. 